\title{
Nueva visión mundial de la economía: integración de saberes hacia el cuidado del sistema ecológico
}

\section{Silvia Eugenia Campuzano Fernández', Gloria Mercedes Cortés Saavedra², Andrea Marcela Turriago Campuzano 3}

1. Coordinadora de Trabajos de Grado y docente investigadora de la Facultad de Ciencias de la Salud, Programa de Bacteriología, Universidad Colegio Mayor de Cundinamarca - UCMC.

2. Docente Investigadora, Maestría en Ciencias Económicas. Universidad Santo Tomás de Aquino USTA.

3. Profesional en Finanzas y Relaciones Internacionales, Universidad Externado de Colombia. Investigadora Grupo BAZERI.

Correspondencia: scampuzano@unicolmayor.edu.co

Recibido: 18-11-2011/ Aceptado: 20-12-2011

\section{Resumen}

El presente artículo responde a la necesidad de cubrir espacios de intervención en el manejo de los residuos en PYMES productoras de residuos peligrosos, mediante la aplicación de estrategias de prevención, centradas en la aplicación de un modelo educativo que genere beneficios económicos, sociales y al medio ambiente.

La intervención para la solución de esta debilidad se presenta desde la integración y trabajo mancomunado universidad empresa, con el aporte significativo de cada uno de los escenarios, representados en el conocimiento y capacidad de investigación que caracteriza a la universidad como constructora del conocimiento y la empresa como agente relevante en el ciclo económico y productivo.

Palabras clave: residuos peligrosos, contaminación, economía ambiental, política social, educación.

\section{Abstract \\ The economy's new sight in the world: integration of knowledge for the care of the ecological system}

To give response to this necessity, it's required the integration of different sciences which brings an exhaustive learning, in order to integrate knowledge's such as economical, educational and environmental management, to resolve a problem that harms the community, giving an efficient control in the degradation of the dangerous wastes, which have impact in the quality of life, owing to the negative impact, related to the care and preservation of the environment.

For the solution of this weakness, it appears the intervention and integration of an essential teamwork university - company, join with the significant contribution of each one of the scenes, represented in the knowledge and capacity of research, that characterizes the university as a construction of the knowledge, and the enterprise as a relevant agent in the economic and productive cycle.

Key words: dangerous waste, contamination, environmental economy, social policy, education. 


\section{Introducción}

En este artículo, la secuencia temática se aborda desde las conceptualizaciones de la economía como eje central que soporta la gestión ambiental para conducir a un desarrollo sostenible que asegure una buena calidad de vida. En consecuencia se hacen planteamientos soportados desde la visión económica, luego se tendrá en cuenta el aspecto educativo como elemento que permite generar cambios de conducta en los individuos y por último se relaciona la parte operacional que hace referencia al manejo de los residuos en particular.

La aplicación de la gestión ambiental en el manejo de los residuos peligrosos, determina que la intervención de la problemática ambiental desde cualquier concepción, es un tema que tiene un carácter holístico y está influenciado por consideraciones culturales, territoriales y temáticas. Teniendo en cuenta estas características se deduce la necesidad de aplicar métodos de mediación, que comprometan la transdisciplinariedad, complementariedad e interdependencia entre los procesos y las dinámicas que se dispongan para la resolución del problema a solucionar.

Es evidente, que la investigación en el área ambiental debe realizarse en función de los factores sociales, culturales, económicos y políticos que los determinan y que se encuentren relacionados en cada caso particular y es en este sentido que se desarrolla la presente propuesta encaminada a resolver diversas preguntas, relacionadas con la interacción de saberes en la resolución de la problemática del manejo de los residuos, desde la concepción económica, social y política relacionada con la implementación de la educación, como fortaleza en la aplicación de las medidas de prevención, para intervenir el control del riesgo biológico que acompaña el proceso del manejo de los residuos y la intervención directa y particular de la gestión ambiental, relacionada con la capacidad de las PYMES de generar producción limpia, con el compromiso de aplicar los principios sanos del desarrollo sostenible .

La gestión ambiental ha cobrado importancia porque incluye el análisis de las situaciones comprometidas en la alteración del medio ambiente generadas por los mismos individuos y que en la actualidad se ven representadas en toda la problemática ambiental, con impacto en agua, aire, suelo y biodiversidad, la cual afecta directamente el medio ambiente, la seguridad alimentaria y el deterioro de la salud de la población (1).

En este contexto, es evidente que se busque integrar las necesidades y aspiraciones de la población, con la protección y recuperación de los ecosistemas regionales que conlleven al aprovechamiento responsable de sus recursos y son precisamente estos postulados los que se han denominado: desarrollo sostenible.

El desarrollo sostenible tal como lo definen las Naciones Unidas, es aquel que permite mejorar la calidad de vida humana sin rebasar la capacidad de carga de los ecosistemas que la sustentan. Este desarrollo implica una transformación progresiva de la economía y la sociedad. Es en este marco que toma relevancia y se hace indispensable la gestión ambiental y con ella la educación, la participación y comunicación como estrategia política, en la generación de condiciones propicias para el desarrollo sostenible (2).

El profesor Herman Daly, economista ecológico que desarrolló políticas y directrices relacionadas con el desarrollo sostenible en el Banco Mundial, afirma que el sistema económico esta destruyendo el medio ambiente en el afán de crecer sin tener en cuenta los límites; con el ejemplo clásico de la relación de las leyes de la termodinámica con los análisis biotecnológicos.

De la misma forma, resulta relevante resaltar el planteamiento del profesor Daly en su libro sobre Economía y ética "Para el bien común", en el que expresa que se vive en una economía creciente, la cual es parte del ecosistema de la tierra que no es capaz de crecer, de acuerdo a la exigencia, en consecuencia no es posible consumir mas de lo que produce el planeta. El hombre se está acostumbrando a sacrificar productos naturales para crecer y esto es mucho más de lo que se puede obtener (3).

Se ha determinado que el impacto financiero y ambiental de la contaminación que se puede generar, afecta negativamente a toda la sociedad, con la generación de desequilibrios económicos que alteran la balanza de progreso de los países. 
Al revisar la política ambiental en nuestro país, el tema de la educación ambiental constituye una de las estrategias fundamentales para reducir el deterioro ambiental, que pueda surgir por diversas situaciones y se propone el desarrollo de una nueva concepción de la relación sociedad-naturaleza. En consecuencia el producto que se pretende brindar a partir de la presente investigación, es precisamente adecuar un modelo educativo, que aporte las directrices de manejo de los residuos en las Pymes (4).

Se pretende direccionar a la sociedad hacia el desarrollo sostenible humano y en esta dimensión se posiciona la educación ambiental, como la acción que permite una construcción colectiva de nuevos valores, que conduzcan a cambios en los ámbitos sociales, económicos y ambientales.

Esta propuesta debe estar inmersa desde la concepción de la investigación, que sea capaz de generar reflexión crítica, en la visión integradora y de proyección a la resolución de problemas, acompañada de un trabajo permanente de análisis y síntesis de la lectura de contextos, que en el presente caso se representa en el manejo adecuado de los residuos peligrosos y en la construcción de explicaciones para la comprensión de problemas ambientales, que para el caso particular se representa en un modelo apropiado de manejo de residuo peligroso.

Así mismo, en la actualidad, la globalización resulta ser el principal actor mundial dada la integración económica, pese a la falta de interés por parte de los actores económicos para implementar medidas regulatorias que promuevan la actividad económica mediante la protección del medio ambiente, para contribución al desarrollo sostenible, sumado a la gestión ambiental en donde se vea implicada la población civil, tomando parte en la decisión de minimizar el impacto negativo, generado por los desechos tóxicos.

Es así, como la economía ambiental surge con el propósito de minimizar dicho impacto a través de mecanismos que conlleven a la optimización de los recursos naturales, cuyas reservas son escasas, razón por la cual resulta indispensable la conservación de los mismos y su óptimo uso mediante la implementación de mecanismos, que conlleven a concientizar a la población a través de la educación.
De esta forma, la economía ambiental en el marco de la economía del bienestar y de la microeconomía, abarca el estudio de los problemas ambientales, empleando herramientas y modelos de la economía, que no solo abarcan temas sobre decisiones de negocios y obtención de rendimientos en la empresa, sino que además; se enfoca en las decisiones que deben realizar los actores económicos, para lograr un óptimo uso de los recursos escasos y lograr la reutilización de los mismos de manera eficiente y efectiva ( 5-7).

El anterior planteamiento conduce al planteamiento de la pregunta: ¿Por qué causar el deterioro del medio ambiente? La respuesta a esta pregunta conduce a establecer que existe una falta de respeto en la cultura de la sociedad hacia el medio ambiente, que no le enseña a cuidar los recursos, sumado a la carencia de ética o simplemente una actitud pasiva de los actores económicos y la sociedad que no se ha concienciado del daño que le esta ocasionando a su propio medio. El cuidado de los recursos naturales no puede permitir una actitud pasiva, sino que requiere de un trabajo activo, conjunto e inmediato, por medios que realmente propongan soluciones y no agraven la condición actual.

En el proceso de planificación ambiental se deben considerar las operaciones normales y anormales dentro de la organización y las condiciones potenciales de emergencia. El proceso de identificar los aspectos ambientales significativos asociados con las actividades de las unidades operativas, debe tomar en cuenta, cuando sea del caso: emisiones al aire, descargas al agua, manejo de residuos, contaminación de la tierra, impactos sobre las comunidades, uso de materias primas y recursos naturales, otros asuntos ambientales locales.

En el caso particular del presente estudio, la atención se centra en la importancia de intervenir el manejo de los residuos peligrosos generados en pequeńas y medianas empresas denominadas PYMES, las cuales presentan características propias de desempeño, con prioridades de inversión en el proceso de producción, que les permita mantenerse en el mercado, teniendo en cuenta otros aspectos importantes como la producción limpia y el manejo adecuado de residuos que permitan prevenir la contaminación ambiental. 
Las mejores propuestas para alcanzar la protección y preservación del medio, están en la concienciación de las personas, en sus ámbitos de consumo, y de la responsabilidad inherente de las instituciones privadas y públicas a crear incentivos, que conduzcan a los consumidores a tomar decisiones de prevención de este daño, a través de la reutilización de los recursos, como es el caso de los desechos.

Es evidente el problema que se presenta en el medio ambiente por el inadecuado manejo de los residuos los cuales generan grados importantes de contaminación, situación que debe ser intervenida especialmente desde la prevención. En consecuencia, para hacer un aporte significativo frente a esta problemática el interés del presente estudio es demostrar ¿̨or qué es importante la integración de áreas del conocimiento en la resolución de problemáticas ambientales?,¿¿Qué se espera con la integración de saberes en el manejo de residuos en PYMES y por último ¿Cómo se logra esta integración?

El caso de referencia se relaciona con la integración de la economía, con un enfoque de economía ambiental, la educación ambiental y la contaminación del medio ambiente, para dar solución a la problemática del manejo inadecuado de residuos en las PYMES con fundamento en el diseño de estrategias de prevención centradas en un modelo educativo de control.

De acuerdo a la política ambiental en nuestro país, se ha determinado que los problemas del ambiente no pueden ser tratados solamente desde la dimensión natural, fisicoquímica y biológica, sino que se requiere considerar simultáneamente, la dimensión humana, es decir, tener en cuenta las condiciones demográficas, psicosociales, técnicas, económicas, sociales, y culturales.

\section{Desde la visión de la economía ambiental}

\section{Intervención y operatividad económica: antecedentes}

Se ha podido determinar que los problemas ambientales se encuentran directamente ligados al crecimiento económico, como consecuencia del gran desarrollo industrial de la posguerra, representado en la polución de las aguas (desechos de las centrales térmicas), del aire (circulación de automóviles) y del suelo (utilización abusiva de abonos y pesticidas). Estos problemas que vienen presentándose desde hace varios ańos, no se han intervenido de manera adecuada y su efecto acumulado es una de las causas del deterioro ambiental actual.

El medio ambiente no puede ser analizado teniendo en cuenta únicamente la visión del desarrollo. En este punto, es importante establecer diferencias entre desarrollo y crecimiento. El concepto de crecimiento se relaciona directamente con lo cuantitativo, es decir, funciona desde una lógica económica de productividad y rentabilidad máxima a corto plazo. El concepto de desarrollo, por su parte, se refiere a la satisfacción de las necesidades y aspiraciones de la población. En efecto, la disponibilidad de recursos, la organización del espacio, la preservación de la calidad del medio, son aspectos importantes de la problemática ambiental y condicionan el bienestar individual y social. Así, la manera como se interviene el ambiente (como se trabaja o se recupera) repercute sobre el nivel de desarrollo y las políticas ambientales son reveladoras de un tipo de ética social.

Las relaciones entre medio ambiente, energía y economía se han puesto de presente en los últimos ańos como consecuencia de los procesos de desarrollo económico, las crisis energéticas y ambientales y las críticas a los presupuestos epistemológicos de las distintas ciencias y los cambios que éstas están efectuando.

La importancia de la inclusión de la economía en la preservación del medio ambiente, radica en la definición que encierra esta ciencia en sí misma, de esta forma la economía puede ser definida como: "el estudio de los mecanismos en que la sociedad gestiona la transformación de los recursos naturales en productos y servicios finales para que sean utilizados y administrados por ellos mismos, de una manera correcta y prudente, ya que éstos son escasos. De esta forma, promueve la creación de nuevos métodos de equitativa distribución de los recursos escasos entre los diferentes individuos de una sociedad, familia o estado. A su vez, trata el tema de cómo logra el hombre sus ingresos y cómo los invierte, haciendo referencia específica en las empresas" (7).

Se observa entonces, como la definición misma de la economía, hace referencia al cuidado, utilización 
eficaz y equitativa distribución de los recursos naturales. Sin embargo, las fallas respecto a este tema se han generado debido a la preocupación por generación de ingresos, mayor valor e inversión hacia las empresas, por la ausencia de modelos económicos eficaces para responder a las necesidades medioambientales y por esta razón que hoy en día el tema del medio ambiente se ha tornado en una problemática mundial.

\section{Desarrollo sustentable un concepto a tener en cuenta}

Concepto usado según Jiménez (1997) (8) frecuentemente en términos económicos. Es decir el que tiene la capacidad de mantener su progreso continuamente, ó sostenibilidad (sustentabilidad) de un ecosistema definida como la capacidad para mantener con el tiempo la vitalidad de sus componentes y los procesos de funcionamiento, teniendo en cuenta sus características.

Su estructuración conceptual se obtiene por la interrelación entre la noción ecológica de resiliencia y la noción social de equidad (sostenibilidad o sustentabilidad), incluyendo la variable tiempo e involucrando el sistema económico, lo cual se refuerza con el planteamiento de Roberto Guimarães, 2003 (9); la sustentabilidad requiere un mercado regulado y un horizonte a largo plazo.

Teóricamente maneja la complejidad de las Interrelaciones sociedad-naturaleza, donde la utilización de los bienes ambientales depende de determinadas realidades económicas, técnicas, sociales y culturales, las cuales condicionan la evolución de los sistemas sociales y naturales.

Además se impulsa un desarrollo (desarrollo sostenible global) que garantiza la sostenibilidad del sistema humano y ambiental, con la sostenibilidad ecológica, económica y social de todos los subsistemas interrelacionados. Se tienen como principios la ética, equidad social y solidaridad con el futuro, lo cual supone según Jiménez (2007) (10) reformular a partir del desarrollo sostenible el orden económicoecológico mundial (cooperación internacional) y definir una nueva economía del desarrollo sostenible o economía ecológica (adaptación ambiental del sistema dominante).

\section{Visión desde el marco económico}

Se relaciona con la habilidad de mantener la productividad (ecosistemas) a pesar de las tensiones intensas y grandes perturbaciones, logrando un rendimiento económico óptimo, siendo preferible un sistema (como el agrario) con mayor productividad, estabilidad, sostenibilidad y distribución equitativa.

Jiménez, et al. 1997 (8) plantea una reformulación de la economía mundial y de la teoría económica para aprender a vivir equitativamente de las rentas que produce el capital natural sin consumir irreversiblemente esta riqueza de difícil reemplazo (integración economía-ecología), integrándose un equilibrio dinámico con el medio ambiente (condición previa para asumir la sostenibilidad del desarrollo en los demás sistemas humanos).

\section{Importancia del medio ambiente en el marco internacional}

La problemática que surge como consecuencia del ineficaz manejo de los recursos naturales y del medio ambiente ha dado lugar a la creación de un marco normativo internacional, fundamentado en la preocupación por el desarrollo, el crecimiento y la pobreza en los países en desarrollo.

Desde 1972 se han realizado reuniones específicas, con el propósito de cuestionar el modelo económico perjudicial para el medio ambiente, como fue la Conferencia de las Naciones Unidas sobre el Medio Humano, en la cual se estableció que el subdesarrollo de los países en desarrollo, era la principal causa de los problemas ambientales. Así mismo, los grados de miseria de estos países contribuyen a la contaminación, ahondando el problema.

La UNESCO y el PNUMA crearon un modelo alternativo de desarrollo en 1974. La ONU también creó la Comisión Mundial sobre el Medio Ambiente y Desarrollo en 1987, emitiendo el Informe Brundtpland Nuestro Futuro Común, que delimitaba el uso de los recursos naturales con el propósito de generar el concepto de desarrollo sostenible para las futuras generaciones, a partir de los principios del ecodesarrollo y la modificación de patrones de consumo.

Así mismo, en los años 90's, surgieron instrumentos de política ambiental, como el Programa de Naciones 
Unidas para el Desarrollo PNUD, el cual sustentó el Índice de Desarrollo Humano IDH, el cual introdujo indicadores de ingreso nacional, esperanza de vida y grado de educación, y logró dar lugar a la evolución de los controles directos de las políticas de mercado.

De igual forma, La Cumbre de la Tierra como instrumento enmarcado en la Convención de las Naciones Unidas sobre el Cambio Climático CMNUCC, también conocido como: Protocolo de Kioto, celebrado en Brasil y que surgió como marco de referencia para la generación de políticas empresariales y gubernamentales de cuidado y preservación del medio ambiente y sus recursos a través del desarrollo humano sustentable, la protección de los recursos naturales y sociales bajo principios rectores como la integridad ecológica, la justicia social y económica, encaminada hacia la equitativa distribución de los recursos, democracia, no violencia, paz, direcciona las acciones relacionadas a la temática.

En consecuencia, son múltiples los organismos internacionales, que han surgido debido a la preocupación en torno al ineficiente uso de los recursos ecológicos y en busca de un crecimiento económico con calidad, que han dado origen a reglamentos, comisiones y organizaciones especiales y específicas, con el objetivo de encargarse de estos temas como son: el GATT/WTO, la UNCTAD, el PNUMA, el NAFTA y la OCDE.

El GATT o WTO ${ }^{1}$ estableció el Comité sobre Comercio y Medio Ambiente. La UNCTAD busca la interrelación entre las políticas comerciales y las medioambientales a través del consenso de sus países miembros. El PNUMA se encuentra fundamentado en el derecho ambiental internacional, la economía ecológica y la formación ambiental y científica direccionada hacia la preservación

\footnotetext{
${ }^{1}$ Acrónimo de General Agreement on Tariffs and Trade (Acuerdo general sobre comercio y aranceles) es un tratado multilateral, creado en la Conferencia de La Habana, en 1947, firmado en 1948, por la necesidad de establecer un conjunto de normas comerciales y concesiones arancelarias, y está considerado como el precursor de la Organización Mundial de Comercio. El GATT era parte del plan de regulación de la economía mundial tras la Segunda Guerra Mundial, que incluía la reducción de aranceles y otras barreras al comercio internacional.
}

del medio ambiente y sus recursos. La $\mathrm{OCDE}^{2}-$ Organización para la Cooperación y el Desarrollo Económico establece principios regulatorios en materia de políticas ambientales y económicas, e instituyó el principio de: "el contaminador paga" y "el usuario paga". La OMC - Organización Mundial del Comercio estableció en 1995, un Comité de Comercio y Medio Ambiente en la búsqueda de un desarrollo sostenible para los estados miembros. El NAFTA es el primer tratado que involucra de forma amplia, el tema del medio ambiente a través del Acuerdo Paralelo de Cooperación Ambiental (NAAEC). La Unión Europea se desenvuelve en un marco legislativo en bloque, con un mecanismo de funcionamiento diferente, debido a que sus países miembros, están altamente sensibilizados frente al tema de la protección del medio ambiente, la naturaleza y sus recursos.

De esta forma, han nacido nuevos organismos, organizaciones gubernamentales e internacionales, que se preocupan por este aspecto específico, dando origen a programas y proyectos que proponen herramientas, para combatir el problema medio ambiental actual y que promueven modelos que se dirijan a los principales agentes contaminantes, como son las empresas e industrias de cada uno de los países del mundo.

\section{Perspectiva económica del sistema ecológico}

Desde el punto de vista económico se pueden enumerar cuatro funciones específicas del entorno natural que resultan ser razones fundamentales de estudio por parte del sistema económico y que justifican la vital importancia que tienen para el mismo.

- Los recursos naturales son los principales proveedores del sistema productivo.

\footnotetext{
${ }^{2}$ La Organización para la Cooperación y el Desarrollo Económico (OCDE), es una organización de cooperación internacional, compuesta por 31 estados miembros, cuyo objetivo es coordinar sus políticas económicas y sociales. Fue fundada en 1960 y su sede central se encuentra en la ciudad de París, Francia. El principal objetivo es maximizar su crecimiento económico y coayudar a su desarrollo y al de los países no miembros. Se considera que la OCDE agrupa a los países más avanzados y desarrollados del planeta, siendo apodada como club de países ricos. Los países miembros son los que proporcionan al mundo el $70 \%$ del mercado mundial.
} 
- El sistema ecológico funciona como mecanismo de desagüe para los residuos provenientes de las actividades de producción y consumo.

- Son el principal soporte de la vida humana, animal, vegetal y mineral, debido a que brindan la estabilidad al ecosistema y de esta forma, la estabilidad climática siempre y cuando se mantenga un balance ecológico.

- Actúan suministrando servicios de interés y que resultan ser atractivos para el entretenimiento y el goce. En otros casos, resulta ser un medio de lucro, como es el caso de los parques naturales y ecológicos.

La problemática surge al entender que estos recursos no son infinitos, sino que son limitados y por esta razón resulta indispensable que los seres humanos reduzcan el alto impacto negativo que esta afectando de manera irremediable al sistema ecológico, ya que sin él resultaría imposible que existiera cualquier tipo de vida sobre la tierra.

El ritmo de utilización y explotación de los recursos naturales está agotando día a día la disponibilidad de recursos en el futuro, afectando directamente a las futuras generaciones, debido a la rapidez conque estos se ven agotados por las principales corporaciones internacionales. Es esta, la principal razón de crear normativas que generan conciencia a los empresarios de la profunda necesidad de fomentar una contribución con el medio ambiente y minimizar el daño y la sobreexplotación que de él se realiza, ya que poco a poco se está deteriorando al medio ambiente y su sanidad (11).

\section{Visión desde el marco ambiental}

Se supera la contradicción entre conservación y desarrollo, además se resalta la potencialidad de la vitalidad y diversidad de los ecosistemas naturales, tomados como prioritarios, dándole al capital natural un papel estratégico, trascendental, aunque no exclusivo. Jiménez, et al, 1997 (8) menciona la importancia de la adopción de tecnologías limpias, no intensivas en energía y recursos primarios, propiciando su transferencia internacional (desarrollo sostenible global).

Roberto Guimaraes, 2003 (9) propone el término sustentabilidad ecológica que hace referencia a la base física del proceso de crecimiento y cuyo objetivo es la conservación de la dotación de recursos naturales incorporada a las actividades productivas.

Además también incluye el término de sustentabilidad ambiental que trata sobre la capacidad de la naturaleza para absorber y recomponer las agresiones atrópicas.

\section{La economía y la sostenibilidad ambiental}

Son muchos los elementos que Costanza et al.1991 (12) considera antes de definir la sostenibilidad. En primer lugar aclara que la sostenibilidad no implica una economía estática y mucho menos estancada, además llama la atención de la necesidad de distinguir entre crecimiento y desarrollo. El crecimiento económico corresponde al incremento en cantidad, el cual no puede ser sostenible indefinidamente en un planeta finito. El desarrollo económico es una mejora en la calidad de vida sin necesariamente causar un incremento en la cantidad de los recursos consumidos que puede ser sostenible. El crecimiento sostenible es una imposibilidad y el desarrollo sostenible necesita llegar a ser nuestra principal meta de política a largo plazo.

De otra parte, resalta la importancia de mantener el sistema de soporte de la vida y las consecuencias y peligros de ignorar su rol dado que este puede perder la capacidad de repararse así mismo, es decir, los efectos tienden a ser irreversibles y cita además, que por consenso, la sostenibilidad es meramente justicia respecto a las generaciones futuras (Ibid: 8).

Partiendo la definición en donde la sostenibilidad es la cantidad de consumo que puede continuar indefinidamente sin degradar el stock de capital incluyendo el stock de capital natural (cf. Pezzey, 1989; Comission on Environement and Development), muchos economistas asumen que el capital natural y el capital hecho por el hombre son sustitutos más no complementos. En consecuencia ningún factor sería limitante. En contraste, para la economía ecológica el capital hecho por el hombre y el capital natural son fundamentalmente complementarios y además enfatiza en la importancia del factor limitante y de cambio en el patrón de escasez (Ibid.:8).

Para Costanza, la definición de sostenibilidad es también dependiente de la escala en tiempo y espacio que se esté usando. Pero antes de intentar 
determinar la escala de tiempo y espacio correcta para la sostenibilidad es necesario concentrarse en como las diferentes escalas interactúan y como podemos construir una definición de sostenibilidad operativa a multiescala (Ibid.: 8).

Aunque de acuerdo con Costanza et al. el concepto de sostenibilidad debe ser objeto de mayor investigación, la definen como: una relación entre los sistemas económicos y dinámicos humanos y los sistemas ecológicos, ampliamente dinámicos pero normalmente con pequeños cambios, en que 1) la vida humana puede continuar indefinidamente, 2) los individuos humanos pueden prosperar, y 3 ) las culturas humanas pueden desarrollarse; pero en que los efectos de las actividades humanas permanecen con límites, para de esta manera no destruir la diversidad, complejidad y función del sistema ecológico que soporta la vida (Ibid::8).

El crecimiento económico solo puede ser soportado como una meta de política en un contexto en el que la sostenibilidad ecológica y económica global estén por encima de las metas y el crecimiento económico local y los intereses privados (12), no obstante, este no es el caso más común.

Para alcanzar y asegurar la sostenibilidad de los sistemas ecológicos, Costanza propone cuatro estrategias:

- Establecer una jerarquía de metas de planificación y manejo globales, nacionales y locales.

- Desarrollar mejores modelos económicos ecológicos globales capaces de permitirnos ver el rango de los posibles resultados y/o impactos de nuestras actividades actuales.

- Ajustar los precios actuales que reflejen los costos globales e incluyan la incertidumbre.

- Desarrollar políticas que detengan la destrucción del stock del capital natural.

\section{Política para la conservación y sostenibilidad ambiental}

El diseño, desarrollo y simulación de modelos económicos ecológicos (Modelo general de ecosistemas GEM, Modelo económico-sistema ecológico STELLA I-III, cuatro visiones de futuro) para valorar los ecosistemas, sus servicios, el progreso tecnológico y sus límites han sido utilizados como herramientas para el análisis, toma de decisiones y diseńo de políticas para la conservación y la sostenibilidad ambiental en Costanza et al. (1998) (13) y (2001) (14) y aunque no es claro de qué manera Costanza participa en el diseńo de políticas e instrumentos de política ambientales, en la introducción del libro "Ecological Economics. The Science and Management of Sustainability" en equipo con Daly y Bartholomew, hacen algunas recomendaciones al respecto en Costanza (1991)(12).

En primer lugar, llaman la atención sobre la necesidad de instituir una meta respecto a la sostenibilidad común a todos los niveles y de aumentar el nivel de conciencia de las instituciones y de las personas respecto a la sostenibilidad ecológica. Los autores proponen, además, el uso de auditores ecológicos y a manera de ejemplo recomiendan que el Banco Mundial y demás instituciones similares exijan a los diferentes proyectos el siguiente criterio: para recursos renovables, que su tasa de extracción no exceda la tasa de regeneración y que la tasa de generación de desechos no exceda la capacidad de asimilación del ambiente. Para recursos no renovables, que la tasa de generación de desechos no exceda su capacidad de asimilación y que la disminución del recurso requiera el desarrollo de sustitutos renovables comparable para este recurso.

En segundo lugar, resaltan el mantenimiento del stock de capital natural como una condición mínima necesaria para la sostenibilidad. Considerando que no se conoce la necesidad mínima de capital natural sostenible, proponen que se asuma al menos provisionalmente, que nos encontramos en o por debajo del nivel mínimo de capital natural y en consecuencia, no se permita que decline aún más, de lo contrarío se pondría en riesgo la sostenibilidad del planeta.

En tercer lugar, abordan de manera general el tema de instrumentos de política en el cual destacan la necesidad de usarlos en el camino de construir y asegurar la sostenibilidad y proponen los criterios que se deben tener en cuenta para usarlos: equidad, eficiencia, validez científica, consenso, frugalidad y efectividad ambiental.

En cuarto lugar, plantean la necesidad de desarrollar la transdisciplina tanto en el área laboral 
como académica y de combinarla con un énfasis en el valor de la educación general y el desarrollo personal, en contraste con el entrenamiento limitado de profesionales especializados. Dentro de esta propuesta, resalta la necesidad de promover la formación de economistas ecológicos que conozcan y articulen la economía y la ecología.

En quinto y último lugar, presentan su visión acerca de las instituciones en donde afirman que faltan instituciones con la flexibilidad necesaria para ocuparse del desarrollo sostenible. Muchas instituciones financieras continúan con el supuesto de continuar el crecimiento exponencial, otras tienen una fragmentación entre mandatos y políticas y no usan las fuerzas de mercado para solucionar los problemas ambientales o no cuentan con análisis costo - beneficio adecuado. Lo anterior, como consecuencia de la falta de conciencia y educación acerca de la sostenibilidad, el ambiente y las causas de la degradación ambiental y de la inflexible estructura burocrática.

\section{De los sistemas ecológicos}

Como se mencionó en la introducción, el análisis y la síntesis que Costanza realiza de los Sistemas Ecológicos van más allá de la comprensión de los sistemas por sí mismos, al observarlos de una manera crítica y en función de su relación con la sociedad. $\mathrm{Al}$ respecto sus planteamientos van en dos sentidos:

El primero, comprender su funcionamiento como base para hacer un uso sostenible de los bienes y servicios que proporcionan para la vida y el desarrollo de la sociedad. De acuerdo con Costanza (12), los sistemas ecológicos juegan un rol fundamental en el soporte de la vida en la tierra en todas las escalas jerárquicas sin el que las actividades económicas serían imposibles. Estos sistemas son esenciales para los ciclos de la materia como el del agua y el del carbono, proporcionan materias primas, alimento, agua, oportunidades de recreación y controlan el microclima para toda la población humana. A largo plazo, una economía saludable puede existir únicamente en simbiosis con una ecología saludable. De la comprensión por parte de la academia, de las instituciones y de la sociedad, de esta dependencia del sistema económico frente a los sistemas ecológicos depende evitar distorsiones y debilidades de manejo y administración.

El segundo, considerar los sistemas ecológicos como el mejor modelo para el diseño de sistemas globales sostenibles. Un mejor entendimiento del funcionamiento de los sistemas ecológicos y de cómo se auto mantienen, puede proporcionar ideas y/o aproximaciones de cómo diseñar y administrar sistemas económicos sostenibles. Por ejemplo, en los sistemas ecológicos en clímax ${ }^{3}$ no hay polución, todos los desechos y/o productos son reciclados y usados o disipados en algún lugar del sistema. En consecuencia, un sistema económico sustentable debería caracterizarse por un ciclo cerrado similar al de los sistemas ecológicos en clímax, encontrándole otro uso y reciclando los desechos antes que almacenarlos, exportarlos, diluirlos, o cambiarles su estado y permitirles desestabilizar los ecosistemas en Costanza (12).

Los servicios ofrecidos por los sistemas ecológicos y por el stock de capital natural son indispensables para el funcionamiento del sistema que soporta la vida en la tierra. Estos contribuyen directa e indirectamente al bienestar de la sociedad y representan parte del valor económico total del planeta. Sin embargo, no son totalmente capturados en mercados comerciales o adecuadamente cuantificados en términos comparables con servicios económicos y de capital manufacturado, además frecuentemente les dan poco peso en las decisiones de política. Esta negligencia en última instancia puede comprometer la sostenibilidad del hombre en la biosfera (Ibid.:4). En consecuencia, necesitamos incorporarlos en nuestras cuentas económicas. Para ello, el primer paso es determinarles un valor comparable con el valor de los bienes y servicios económicos, considerando siempre su insustitubilidad y la irreversibilidad de su deterioro.

No es muy significativo preguntarse sobre el valor del capital natural para el bienestar de la humanidad o preguntarse el valor masivo o particular de formas de capital natural, dado que su valor total es infinito. En contraste, si lo es preguntarse como los cambios en cantidad o calidad del capital natural y los servicios ecosistémicos pueden tener un impacto en el bienestar

${ }^{3}$ El clímax corresponde a la etapa final del desarrollo de un ecosistema en la cual este alcanza su madurez y estabilidad. 
humano. Por ejemplo, pequeños cambios en la composición de la atmósfera global puede generar grandes cambios en el clima y afectar el bienestar de la población mundial (Ibid: 6).

Sin embargo, aunque la valoración es ciertamente difícil y preocupante no se escoge si se hace o no. Las decisiones que se toman como sociedad frente a los ecosistemas implican la valoración aunque no necesariamente monetaria. Pero si se puede decidir hacerla con conocimiento explicito de la incertidumbre y de manera consciente o inconsciente según Costanza, et al (13).

Cambios en la calidad o cantidad de los servicios ecosistémicos tiene valor en sí mismos en la medida en que estos generen cambios en los beneficios asociados con las actividades humanas o cambios en los costos de estas actividades. Estos cambios en beneficios y/o costos tienen un impacto en el bienestar humano a través de establecer mercados o actividades de no mercado. Un bosque, por ejemplo, proporciona madera para ser transada en el mercado, y en contraste, el valor del mismo también puede estar asociado a actividades de recreación las cuales no requieren de mercado, según Costanza, et al (13).

El valor de muchos tipos de capital natural y de servicios ecosistémicos puede no ser fácilmente transable en el mercado y la información acerca de su contribución en el bienestar es pobre. Sin embargo, los economistas han intentado determinar su valor a partir de lograr que las personas revelen su disponibilidad a pagar por los bienes y servicios ecológicos en un servicio hipotético.

Un método alternativo para estimar el valor ecológico asume una base biofísica según Costanza (12); Costanza et al. (13). Esta teoría sugiere llegar a valorar cosas de acuerdo a cuánto cuesta producirlas y este costo está en función de cómo están organizadas en relación con su ambiente en Costanza, et al. (12).

Bajo este marco, Costanza, et al (13) realizaron una primera valoración de los servicios ecosistémicos y del capital natural, el fue limitado por varias razones:

1) Algunas categorías de servicios ecosistémicos no han sido suficientemente estudiadas. Además, no fue posible identificar estudios de valoración de algunos biomas mayores como los desiertos, la tundra y los hielos polares.
2) Los precios corrientes que forman la base de muchas de las estimaciones de valor, son distorsionados dado que excluyen el valor de los servicios ecosistémicos, el trabajo doméstico y la economía informal. Además, hay diferencias entre el valor total, el excedente del consumidor, el excedente del productor y demás variables que son usadas para estimar las unidades de valor.

3) Muchos de los estudios de valoración utilizados se basan en la disponibilidad a pagar de los individuos por los servicios ecosistémicos, estos individuos pueden no estar bien informados $y$ sus preferencias pueden incorporar de manera inadecuada justicia social y sostenibilidad ecológica, entre otros objetivos importantes.

4) Para realizar el cálculo del valor corriente, generalmente se asume la curva de oferta y demanda tradicional, pero en realidad la curva de oferta de muchos servicios ecosistémicos tiende a ser una línea vertical inelástica, que tiende hacia el infinito cuando la cantidad tiende a cero. Así, el excedente del consumidor, del productor y en consecuencia, el valor total de los servicios ecosistémicos se aproximaría también a infinito.

5) La valoración realizada no considera un límite y la irreversibilidad en la función de respuesta de los ecosistemas. En consecuencia, la valoración subestima el valor total.

6) La extrapolación de los valores puntuales estimados en un valor global introduce error.

7) Aunque los ecosistemas son aptos para ofrecer varios servicios de manera simultánea e indefinidamente, este no siempre es el caso. El sobreuso de un ecosistema puede limitar la oferta de un determinado servicio. En consecuencia, se puede dar un doble conteo. Este error se puede evitar usando un modelo de equilibrio general en cambio de uno de equilibrio parcial como el usado, dado que este permite incorporar directamente la interdependencia entre la función y el servicio ecosistémico. No obstante, se usó un modelo de equilibrio parcial dado que este se adaptaba mejor a la escala de la investigación.

8) La estimación de valor asume un modelo estático y por lo tanto ignora la complejidad 
e interdependencia entre los servicios ecosistémicos.

9) No se incorporó el valor de la infraestructura del ecosistema, lo cual conduce a una subestimación del valor.

10) Aunque intentó corregirse, los valores se ven afectados por las diferencias de los ingresos de cada país.

Como consecuencia de las dificultades inherentes y de la incertidumbre para determinar valores de los bienes y servicios ecosistémicos, la economía ecológica reconoce varias aproximaciones metodológicas para realizarla, y aunque no hay un consenso sobre cuál es la mejor aproximación, si lo hay acerca de que la mejor valoración de los servicios ecosistémicos es una meta importante de la economía ecológica según Costanza et al. (12). Además, Costanza et al. (13) consideran que es un ejercicio esencial para: primero, definir un rango de valores potenciales de los servicios ecosistémicos más evidente; segundo, establecer una primera aproximación de la magnitud relativa de los servicios ecosistémicos globales; tercero, ofrecer una línea base para su posterior análisis; cuarto, proporcionar un punto de partida para aquellas áreas que requieren investigación adicional; y quinto, estimular la investigación adicional y el debate.

\section{De las externalidades}

Para cambiar el tipo de residuos indeseables por alguno deseado se requiere hacer modificaciones al proceso. Estas se hacen o se evitan bajo consideraciones económicas inmediatistas. Desde una perspectiva de la economía ambiental Tchobanoglous et al., (1996),(15) proponen que habría que cargar a las utilidades aquellas que obtendrían las generaciones futuras y presentes a partir de las innovaciones o cambios tecnológicos que se efectúan y que del criterio de rentabilidad o de ganancia debe trascenderse para dar cuenta de los costos sociales y ambientales, lo que seguramente permitirá enfocar la aplicación de tecnologías limpias, bien sea mediante manejos especializados de los residuos, cambios en la organización del trabajo o transformaciones físicoquímicas siendo necesario asegurar unos criterios de producción justa y ética.
En la medida en que la economía introduce en los costos directos algunas externalidades negativas, la preocupación por una producción ambientalmente limpia con los menores efectos en la salud de la fuerza laboral y en la salud pública, es una cuestión vital para la competitividad de las empresas. El problema más grande en un sistema de manejo de residuos es su producción. En los procesos productivos se encuentran varias fuentes de contaminación asociadas a efluentes fundamentalmente las aguas residuales, las emisiones gaseosas y los residuos sólidos según Tchobanoglous et al., 1996 (15).

Existe una externalidad según Martínez Alier y Jusmet, 1998 (16) cuando la actividad de producción o de consumo de un agente produce una pérdida o ganancia de bienestar a otro sin que esa pérdida o ganancia sean debidamente compensadas. Además Tchobanoglous et al., 1996 (15) afirma que con medidas alentadoras a un espíritu empresarial ético se espera una mayor eficacia de los procesos industriales, la organización de estrategias preventivas, la incorporación de tecnologías y procedimientos limpios de producción a lo largo del ciclo de vida del producto, de forma que se reduzcan al mínimo o se eviten los residuos, reduciendo así las consecuencias negativas en la utilización de los recursos y el medio ambiente.

\section{Definición económica de la contaminación}

Actividad de producción o consumo que genera pérdidas de bienestar a otro. Existen costos que la sociedad no esta dispuesta a asumir y que hay que internalizar vía negociación o por regulación vía instrumentos económicos o de comando y control o por conciliación, según notas de Castiblanco, 2006 (17).

Una solución alternativa según Martínez Alier y Jusmet, 1998 (16) para reducir la contaminación es aprobar un impuesto sobre la contaminación. Es decir aplicar el principio "el contaminador paga" (impuesto pigouviano). Sin embargo, el nivel óptimo de contaminación no es fácil hallarlo por la insuficiente información en el mundo real, es por esto que no hay forma satisfactoria de definir el valor monetario de muchos impactos ambientales, de esta forma los 
impuestos son posibles instrumentos que presentan ventajas para conseguir objetivos ambientales fijados políticamente.

Las medidas contra la contaminación y los costes de reducir los impactos ambientales

En este sentido pensamos en dos tipos de posibles efectos de un impuesto sobre la contaminación: cambiar los niveles de producción y con ella la contaminación asociada o cambiar las técnicas productivas estimulando tecnologías más limpias y así reducir la cantidad de emisión por unidad producida. Para ello es necesario que se grave directamente la contaminación.

El concepto de mitigar o reducir según Martínez Alier y Jusmet, 1998 (16) tiene un significado claro en principio: el coste monetario dadas las posibilidades tecnológicas de implantar dichas medidas, pero cuando nos referimos al coste social que implica que las empresas adopten dichas medidas, eligiendo la mejor opción que representará reducir la contaminación se pueden presentar las siguientes situaciones :

- Medidas de uso más eficiente de los recursos o reaprovechamiento o comercialización de residuos, la reducción de la contaminación no será costosa sino que incluso puede reportar un beneficio monetario, lo cual es socialmente conveniente.

- Disminuir la producción o determinadas actividades, será muy difícil determinar el coste monetario social de dicha reducción, no es claro si la medida tendrá para la sociedad un coste positivo a largo plazo.

- Si efectivamente se reduce la producción global de un bien, los costes sociales de dicha reducción también son fáciles de medir :excedente del consumidor, por lo tanto solo se valorará la pérdida introduciendo análisis referentes a la elasticidad de la demanda, de manera que lo único que cuentan son las demandas solventes, medidas monetarias de cambios en el bienestar.

Disminuir un poco la contaminación no resulta muy caro, pero disminuirla mucho es relativamente más caro. Los costes marginales pueden ser crecientes a medida que disminuye la contaminación, siendo la idea de una dificultad cada vez mayor para reducir la contaminación.

\section{Instrumentos económicos para el} control de la contaminación ambiental

En las notas de Castiblanco, 2006 (17) los instrumentos económicos se utilizan para mitigar la contaminación ambiental o incentivar comportamientos amigables con el medio ambiente en el sector productivo, evaluando la estructura de costos para que sea más rentable para el productor alcanzar la meta a menor costo, según el tipo de instrumento que escoja:

- Tasas e impuestos a las emisiones, a los insumos contaminantes por uso.

- Subsidios a uso insumos no contaminantes, a tecnologías limpias

- Sistemas de Permisos negociables (creación de los mercados ambientales).

- Incentivos tributarios para la inversión ambiental

- Líneas de crédito especiales para el financiamiento de la inversión ambiental.

\section{Visión errónea del sistema económico}

La teoría económica no ha logrado integrar aún en su marco de análisis, la importancia que desempeñan los recursos en la estructura económica y por esta razón no la concibe dentro de la visión de las actividades analíticas económicas. La visión de la economía respecto al proceso económico esta reflejado como un diagrama circular en el que no hay entradas ni salidas de materia y energía en el que las empresas y las familias intercambian bienes, servicios y dinero, como se observa en la Figura 1.

En la Figura 1 se evidencia que el sistema económico tiene una tendencia a ignorar que los bienes y servicios intercambiados en los mercados son producto del ámbito material y ecológico, e ignora a su vez, las teorías y modelos químicos y biológicos porque se enfoca únicamente en el crecimiento económico. En la Figura 2 se observa como debe ser el modelo económico frente al tema medio ambiental en el que se consideran los principios biofísicos medioambientales.

En la Figura 2 anterior se observa una tendencia diferente en el ciclo debido a que el sistema económico se convierte en un subsistema dentro del ecosistema, donde hay un flujo de energía, materiales biológicos 
Pagos por al compra de bienes de consumo

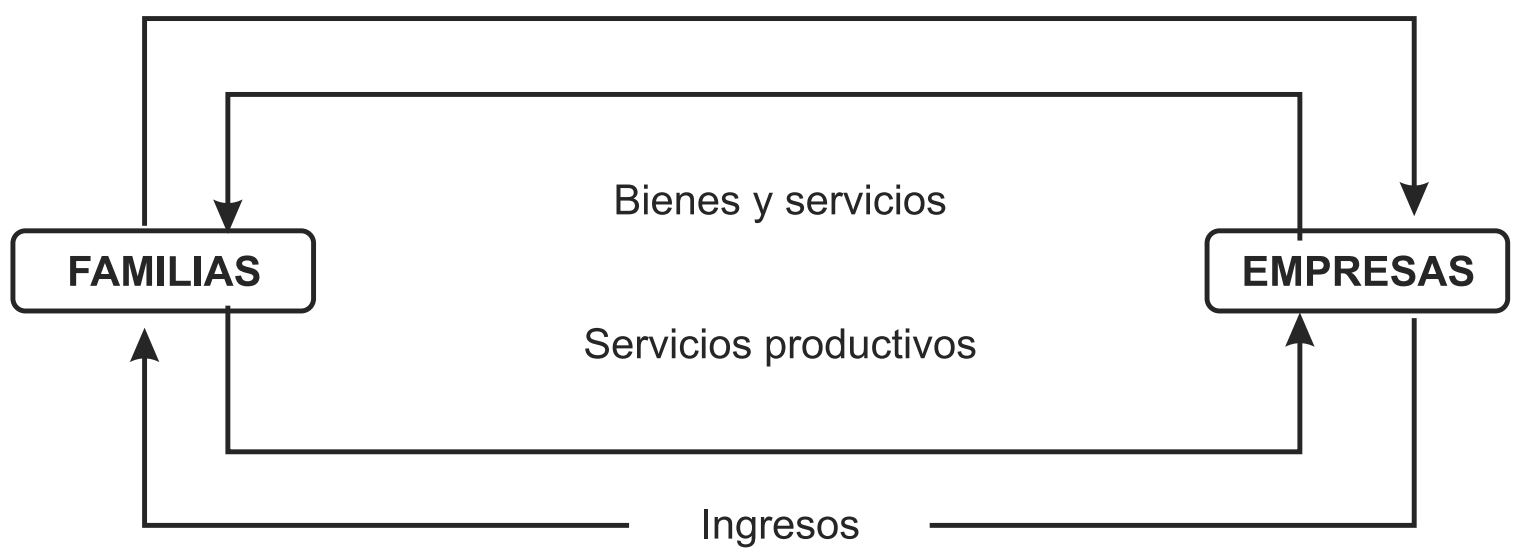

Figura 1. Visión de la economía del sistema económico. Fuente: adaptado de Hall et al (2001, p. 664)

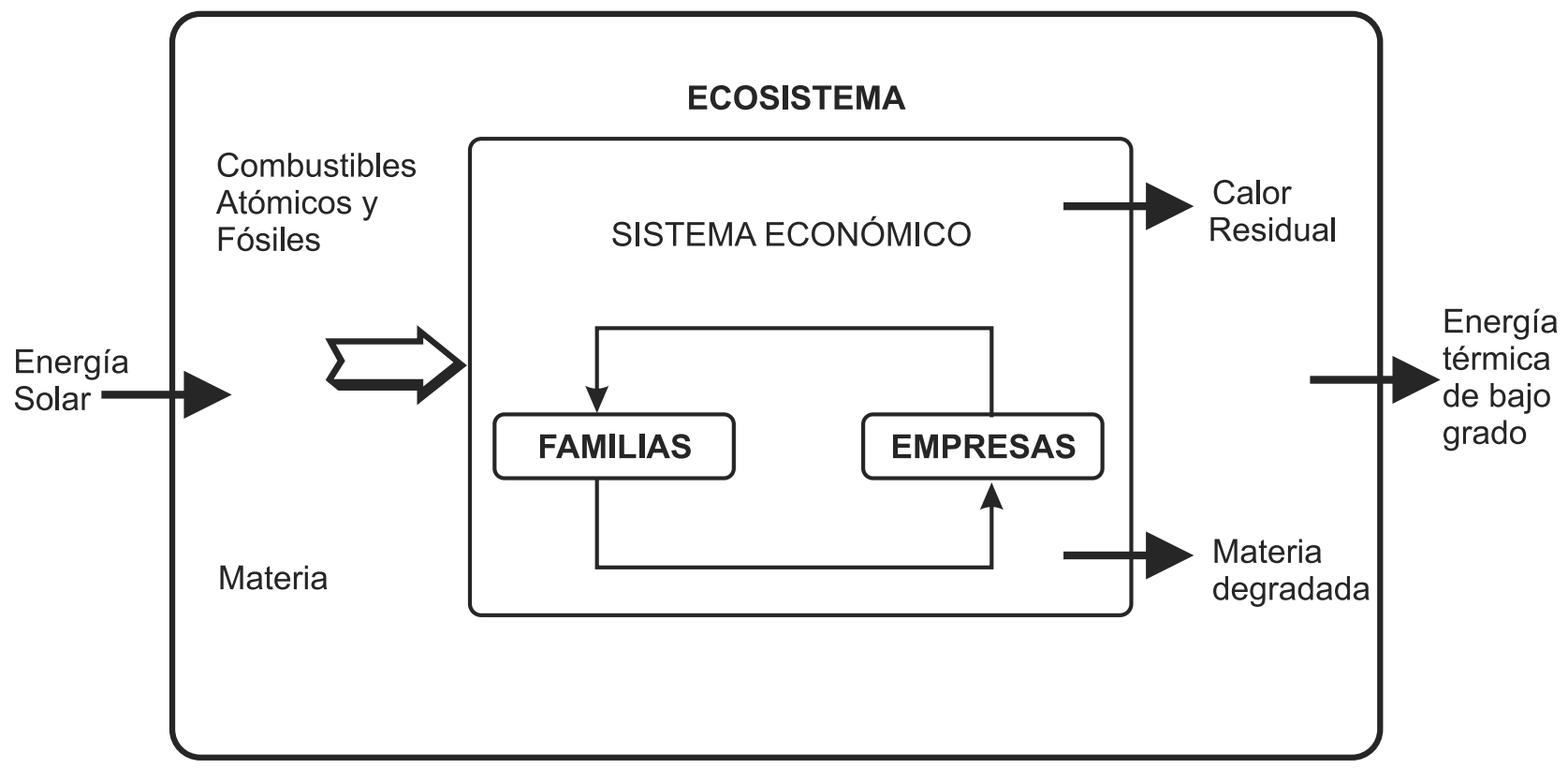

Figura 2. Visión biofísica del sistema económico.Fuente: adaptado de Hall et al (2001, p. 664)

y procesos de absorción y excreción de recursos que caracterizan el proceso económico, como son la producción y el consumo. Por esta razón, la economía ha tenido una transformación socio-económica atada a la capacidad humana de intervenir, manipular y utilizar los recursos naturales y energéticos disponibles, tanto los renovables como los no renovables para los procesos productivos y consuntivos.
Esta transformación acelerada producida por los diferentes agentes económicos como son: Estado, industrias, productores y consumidores han conducido a la diversas formas de contaminación ambiental como consecuencia de la aceleración y optimización de procesos sin tener en cuenta el impacto nefasto que se produce por la aceleración de estos mecanismos, con el propósito de lograr mayor crecimiento 

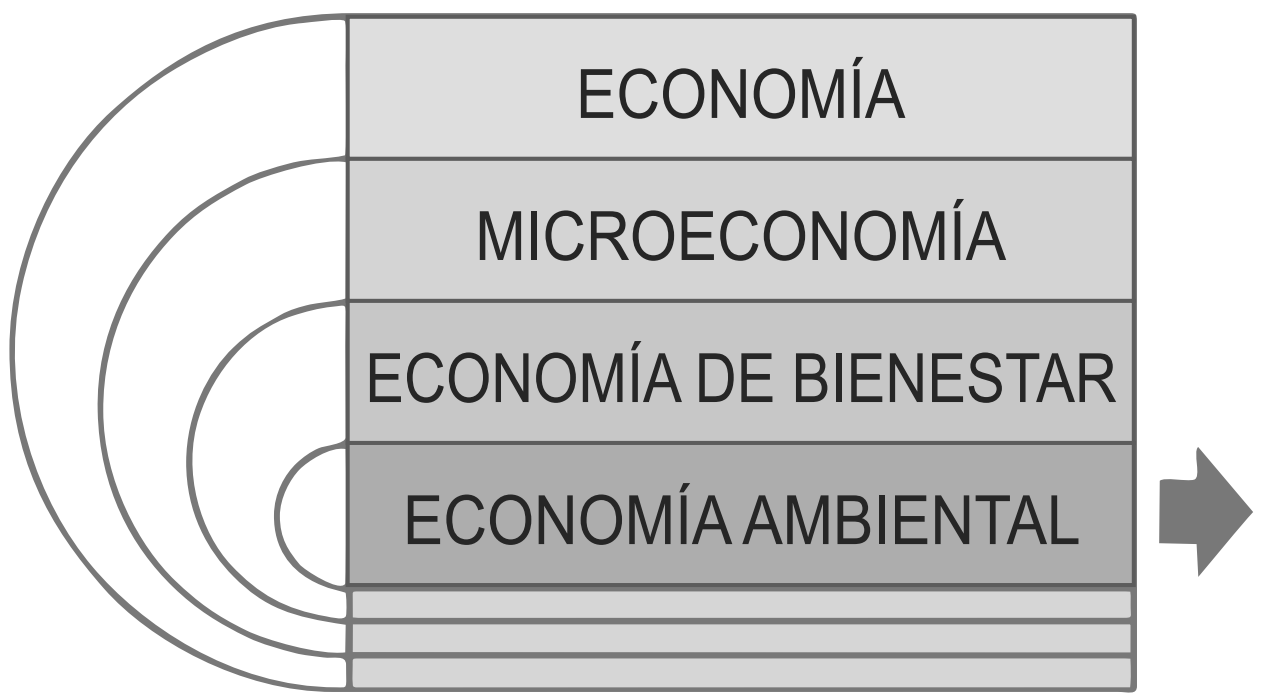

Optimización en la explotación de recursos, medios de gestión ambiental e instrumentos para lograr el desarrollo sostenible.

Figura 3. Optimización en la explotación de recursos, medios de gestión ambiental e instrumentos para lograr el desarrollo sostenible.

empresarial a través de utilidades y crecimiento económico que ha desencadenado crisis energéticas y de abastecimiento, como es el caso de la inseguridad alimentaria que aflige principalmente a los países en desarrollo, quienes carecen de recursos económicos y monetarios necesarios para satisfacer las necesidades principales de la población y que ponen en peligro el mantenimiento de las generaciones futuras.

Esta necesidad ha conducido a que la ciencia económica genere modelos de respuesta a dicha problemática, a través de la inclusión de los recursos naturales en el marco de análisis y de esta forma surge un nuevo concepto de la economía que se preocupa por el medio ambiente y el entorno ecológico de las industrias en todo el mundo, a través de modelos económico - ambientales.

\section{La necesidad de una nueva mirada económica}

La integración e inserción de la economía debe ir de la mano de la implementación de medidas regulatorias que contribuyan al desarrollo sostenible a través de la gestión ambiental en la cual se debe involucrar a la población civil, como un grupo de presión, así como las industrias, el Estado y los demás agentes económicos, productores y consumidores de bienes y servicios con el propósito de generar acción colectiva, en la toma de decisiones y en la práctica de políticas medio ambientales.
La Economía Ambiental, pretende plantear herramientas y de esta forma modelos de análisis que permitan la optimización de los recursos naturales con el propósito de generar un método para minimizar la explotación de los mismos, facilitar la utilización, así como la equitativa distribución, partiendo del concepto de que los recursos son escasos. De esta forma, la economía ambiental surge del siguiente esquema económico, Figura 3

Teniendo en cuenta la Figura 3 y como consecuencia de las crisis ambientales y la restricción al crecimiento sostenido como respuesta a estos fenómenos naturales, la economía tuvo que empezar a crear herramientas e instrumentos para limitar las acciones humanas como la sobreexplotación de recursos que han dado lugar a minimizar la disponibilidad y la calidad y de esta forma promover el cuidado de recursos naturales. Con el surgimiento de la economía ambiental se intenta atender no solo el tema del abastecimiento de los recursos naturales, sino a su vez los daños causados por las empresas al medio ambiente conocidas como las externalidades que causan contaminación debido a la producción de residuos tóxicos que generalmente se generan a través de aguas residuales, mediante procesos de fabricación, surgiendo así dos ramas de la economía: economía de las externalidades y economía de los recursos naturales.

La Economía de las Externalidades se encarga de estudiar las emisiones contaminantes que generan 
costos externos, debido a que los productores que las provocan no los asumen, sino que son terceras personas, las que sufren los daños de la contaminación, generando así fallas, inconsistencias e imperfecciones del sistema de mercado y por esta razón surge la necesidad de crear mecanismos de concienciación a los productores, reduciendo los costos.

Respecto al tema anterior se presentan dos teorías diferentes dadas por los economistas Pigou y Coase. El primero insiste en que se deben intentar corregir las imperfecciones del mercado a través de la evaluación de los costos sociales y transfiriéndolos como costos privados a los productores (empresas) a través de impuestos. De otro lado, Coase postula la realización de ajustes en el marco institucional a través de mecanismos de supervisión, control y monitoreo así como la imposición de derechos de propiedad como mecanismo para que el mercado internalice las externalidades negativas que se le están generando a terceros que no se encuentran directamente involucrados en el proceso de producción Kollinger 2004 (6).

La economía de los recursos naturales se fundamenta en la imposición de precios eficientes de consumo de los recursos naturales tanto renovables como no renovables, teniendo en cuenta las preferencias de la diversidad de poblaciones y generaciones logrando así la eficiente utilización y óptima explotación de los recursos minimizando los desperdicios con la generación de un medio ambiente seguro y sano que conduzca a un impacto positivo en la calidad de vida de los organismos vivos y que contribuye a la buena salud de los seres humanos, animales y plantas, al igual que ofrece calidad en recursos como el agua, el aire y el suelo que son indispensables para la vida.

\section{Tendencias internacionales para la gestión de los residuos en las PYMES}

La importancia que ha cobrado a nivel internacional el tema de la correcta gestión de recursos, conllevo a la realización de Conferencias en materia medio ambiental con el propósito de enseñar a los seres humanos del mundo y en especial a los productores a descontaminar el planeta. Motivo por el cual se han originado métodos para minimizar el impacto negativo dañino para la salud y el medio ambiente con el propósito de prevenir los residuos tóxicos y las externalidades negativas que estos desechos causan a terceros. Algunos de los métodos se describen a continuación:

(i) Reducir la producción de residuos en el lugar de origen debido a que este método permite que haya mayor eficiencia en el ahorro económico. En cumplimiento de esta acción los gobiernos deben impulsar la investigación y la implantación de políticas en las Pymes fomentando los beneficios como: reducción de impuestos otorgando ayudas económicas para implementar las medidas oportunas de cuidado del medio ambiente.

(ii) Darle un debido trato a los residuos producidos impulsando métodos como el reciclaje con campañas de sensibilización a la comunidad. Las autoridades deben ayudar a que se usen adecuadamente los materiales reciclados y a que haya un mercado para ellos.

(iii) Impulsar sistemas de recogida y plantas de tratamiento para facilitar la separación y clasificación de los residuos por su diversidad de componentes a través de la realización de inventarios de productos tóxicos, peligrosos y biológicos.

(iv) Promover la cooperación internacional regulando el tráfico de residuos entre países, para que no se produzcan en otro país los daños ambientales que se generaban en el país que los originaba.

Para concluir, es necesario tomar en cuenta la preservación y la minimización de impactos ambientales considerando que quienes son los responsables de causar este daño, deben ser quienes paguen por él, de una manera responsable, así como los diversos actores económicos que se ven involucrados en el ciclo productivo, deben poner en marchar proyectos y mecanismos encaminados, hacia la búsqueda y mantenimiento del desarrollo sostenido.

El medio ambiente es un tema de constante discusión pero también de acuerdos económicos hacia una gestión ambiental acorde a la realidad económica fundamentados en la cooperación internacional, a través de pactos comerciales teniendo en cuenta que es una tarea de todos y no de algunos ya que la 
implantación y ejecución de programas ambientales resulta indispensable. Por esta razón, la sociedad debe interesarse y de esta forma integrarse en la planeación y ejecución de programas, proyectos y toma de decisiones ambientales que involucran a toda la población mundial como consumidores (18).

Las políticas ambientales mundiales deben continuar siendo discutidas en los foros internacionales y se deben continuar los planes expuestos en esta materia para que los países en vías de desarrollo aprendan nuevos mecanismos de reducción y prevención de desechos y que los países desarrollados implementen nuevas herramientas para el cuidado y preservación de un medio ambiente sano para todos.

\section{La postura epistemológica social y política frente a la construcción de un proyecto colectivo ambiental.}

Frente a los cuestionamientos planteados como eje central del presente estudio, las consideraciones epistemológicas que los sustentan se explicitan a continuación. Es esta la visión que direcciona las políticas que se desarrollan para poder enfrentar la problemática del riesgo generado por el manejo de los residuos y se inicia con la respuesta a la pregunta: ¿Por qué es importante la integración del conocimiento social y político en la construcción de un proyecto colectivo-ambiental?

A la vez, que resulta imposible dejar de reconocer el estado de avance e innovación científica, técnica e instrumental, así como, su influencia en los diversos ámbitos de la sociedad. En estos se incluyen sectores sociales, económicos, políticos, educativos, por área del conocimiento, con el propósito de aproximarse a una visión integral de la problemática socio ambiental. También se privilegia una mirada amplia e interrelacionada del ecosistema humano, biofísico, social, económico, y político.

La mirada sistémica propuesta es significativa porque señala el carácter incluyente del habitat pluricultural y megadiverso, donde el ser humano se desarrolle como persona y desempeñe sus actividades socio-económicas en un ámbito de compromiso y responsabilidad, que lo acrediten apto y competente social y políticamente para vivir en sociedad. En esta preocupación debe interiorizar, entre otros aspectos, los símbolos propios de la cultura imperante, que fortalecen su formación humanística, profesional, artística, creativa, innovadora y competitiva.

Consecuentes con la situación descrita y desde una cosmovisión de mundo en el ámbito del desarrollo sostenible se requiere la integración universal de saberes, metodologías, conceptualizaciones y estrategias que confluyan de manera interdisciplinaria y transdisciplinar a instrumentalizar desde los diferentes campos científicos especializados. Estas áreas se relacionan con los aspectos tecnológicos y técnicos, la autorregulación y el autocuidado del ecosistema. Así el hombre aprende a cuidar "el hogar" que desde el origen de la creación, fue comisionado bajo su cuidado y protección.

En consecuencia, se establecen principios jurídicos, normativas, decretos leyes con articulados y disposiciones legales que se encaminan a ejercer el llamado "control social" que en otras palabras, se refiere a la necesidad de impulsar en la ciudadanía, el compromiso participativo y colaborativo con su habitad, de tal modo, que no sólo se conciencie de resguardarlo y conservarlo, en el presente, sino que también se desarrollen formas alternativas de interacción y gestión que incluyan a las generaciones futuras.

En este sentido, Ángel Augusto Maya, pone de manifiesto en su artículo "Desarrollo Sustentable o Cambio Cultural" la ambigüedad del pensamiento ambiental en los siguientes términos: "El pensamiento ambiental es un planteamiento en formación que, para consolidarse, encuentra en su camino muchos obstáculos epistemológicos. Ello se debe fundamentalmente a la formación del pensamiento moderno. La ciencia dominada por el positivismo ha impulsado la especialización como estrategia básica en el desarrollo del conocimiento".

"Se trata de una ciencia aplicada directamente al manejo tecnológico del mundo. Ello exige la especialización, que parte tanto de presupuestos del racionalismo cartesiano de los postulados del empirismo. La consecuencia ha sido la incapacidad de la ciencia moderna para entender y manejar sistemas y por supuesto para ubicar al hombre dentro del sistema de la naturaleza” (19).

Es así que le corresponde a la sociedad en general con el apoyo de las comunidades científicas, la tarea 
imprescindible de avanzar en la integración social y humanística del conocimiento, a partir de la investigación interdisciplinaria del ecosistema, que permita la apropiación de instrumentos, técnicas y estrategias, tendientes a su comprensión en toda su magnitud, esplendor y complejidad.

De esta manera y no obstante las limitaciones y fallas humanas en su comportamiento y actitudes frente al resto de seres vivos, se esperan significativos avances en materia ambiental. Esto se logrará en la medida en que se entienda que la naturaleza es su lugar de habitación, por lo tanto le impele humanizar las formas de acercamiento a ella (naturaleza), lo cual significa, desde la simple lógica, que una actitud de respeto, le permitirá recuperar la calidad de vida terrestre ahora, y en el futuro.

\section{¿Cómo se logra la integración de saberes particulares?}

Frente a la problemática ambiental y social se pretende la consabida y necesaria integración de saberes. Esta integración debe ser abordada desde las ciencias físico- socio antropológicas, mediada por un análisis crítico con respecto a los daños ocasionados, pero también a la posibilidad de recuperación para su conservación que de una manera consensuada aporte soluciones desde la experiencia conceptual y práctica experimental e instrumental. De esta forma se logrará la construcción de una Cultura Nacional Ambiental que le apueste en la construcción visionaria y futurista representada en signos, valores y símbolos socio ambientales, representativos de la sociedad colombiana, en pro de su identidad multiétnica y pluralista.

Esta construcción a través de procesos interdisciplinarios de investigación Maya 1994 (19), es posible, como parte de la construcción de un programa educativo a nivel nacional y regional, orientado a ubicar entre otros aspectos, las áreas críticas del problema. Especialmente se tendrán en cuenta el manejo socio ambiental, los mecanismos para convocar la atención de los actores científicos, sociales, económicos, entre otros, la necesaria toma de decisiones frente a resultados negativos generados por un tratamiento no pertinente y adecuado de la naturaleza.

En consecuencia, se requiere el diseño de instrumentos de reflexión y análisis sobre la relación sistémica del hombre con la naturaleza físico-social, propuestas educativas y sociológicas de concienciación de los grupos humanos y sociales, que los sensibilice y ańada valor agregado en su actitud y manera de pensar e interrelacionarse con su entorno. Es necesario hacer un llamado a las diferentes organizaciones públicas y privadas, gobiernos, estados nacionales y políticos, para trabajar de manera integral e integradora hacia el logro de este objetivo nacional y universal.

Augusto Ángel Maya en su texto "Desarrollo Sostenible o Cambio Cultural" hace una reflexión que permite ver hasta que punto desde lo ambiental, es necesaria una nueva visión de la formación humanística en la universidad, afirma el autor, "se han construido, sin embargo, al margen del sistema natural, como si el hombre nada tuviese que ver con el resto de la naturaleza. Mientras que las ciencias naturales quieren explicar una naturaleza sin hombre, las ciencias sociales, prefieren un hombre sin naturaleza" (19).

Así, y con base en el convenio suscrito entre las universidades USTA y UNICOLMAYOR, con el apoyo de un equipo interdisciplinario conformado por investigadores-docentes y estudiantes de la maestría en ciencias socio-económicas, naturales y humanas, se privilegia la oportunidad de sacar avante este innovador proyecto político en su esencia, por cuanto su finalidad es educar y sensibilizar a grupos humanos, de diferentes sectores de la economía, sobre la responsabilidad social y compromiso ético y estético, componentes básicos para el logro de una calidad de vida sostenible en el tiempo y en el espacio.

Así, en la medida en que la universidad colombiana apoye este tipo de proyectos, que le apuesten al beneficio colectivo e incidan en la búsqueda de formas de innovar. De igual manera que presenten alternativas de relacionarse con la naturaleza, respetando lo diverso y lo cultural, lo ético y estético, desde el punto de vista humano, físico-natural y social, se tendrá la oportunidad de participar en estos procesos productivos con una clara postura epistemológica, con fuerte repercusión en la actitud colectiva de progreso social y planetario.

\section{La postura y fundamentación desde la contaminación ambiental}

Cuando se revisa el problema de los residuos industriales se encuentra que el núcleo de la 
problemática, es urbana y está en los problemas de la producción, y en las formas de valorar los efectos ambientales de los procesos productivos. Este enfoque conduce necesariamente a mirar los problemas del gasto y la fatiga en el trabajo por fuera de los muros de las empresas a establecer las relaciones salud-fábrica desde una mirada ambientalista. De ahí que sea necesario plantearse posibilidades nuevas de enfocar los asuntos de la "salud", con relación a los problemas ambientales.

No ha sido bien reconocida ni suficientemente ponderada la importancia de los factores de riesgo generados por el inadecuado manejo de los residuos de procesos industriales. Es necesario que se conozcan y den a conocer tales factores de riesgo inherentes a los procesos o cadenas de procesos industriales y que se adopten las medidas necesarias para su control.

Se han identificado los principales residuos industriales líquidos, gaseosos y sólidos en las empresas, así como los principales riesgos para la salud de los trabajadores, que están en contacto con los residuos en industrias y marcos de acción para el manejo de residuos industriales que atenúen o eliminen factores de riesgo para la salud ocupacional y el saneamiento de las industrias y los territorios contaminados. En condiciones de subdesarrollo, países como Colombia, adquieren plantas y procesos productivos prohibidos en otros ámbitos, lo cual hace posible encontrar instalaciones industriales que a la luz de las consideraciones ambientales, jamás deberían haber entrado en operación.

De ahí que, en la medida en que la economía introduce en los costos directos algunas externalidades negativas, la preocupación por una producción ambientalmente limpia, con los menores efectos en la salud de la fuerza laboral y en la salud pública, es una cuestión vital para la competitividad de las empresas. El problema más grande en un sistema de manejo de residuos es su producción. En los procesos productivos se encuentran varias fuentes de contaminación asociadas a efluentes, fundamentalmente las aguas residuales, las emisiones gaseosas y los residuos sólidos. El procedimiento seguido ha consistido en definir un enfoque, delimitar el problema, determinar las cantidades de elementos contaminantes, en un estudio de tamiz y sugerir políticas, operaciones y procesos de transformación para reducir la contaminación.

En la definición del problema, siempre resulta esencial determinar el grado de riesgo que el contaminante tiene para con las personas vinculadas directamente al proceso productivo, ubicando allí sus condiciones de salud ocupacional, e igualmente determinando el grado de riesgo que el contaminante representa para la salud pública. Es claro que la conversión de un elemento en objeto de trabajo, así como la aparición de residuos y desechos industriales, no es al azar, sino que depende de las posibilidades tecnológicas de su producción y manejo y de las ventajas e internalidades positivas que tenga para el proceso productivo, además, de las ganancias o costos que su uso o desuso pueda conllevar para los productores, en el marco de la dinámica del mercado.

Puede decirse que las motivaciones económicas, en particular la expectativa de mayores beneficios, es el principal factor que ha impulsado cambios tecnológicos en muchos casos adversos a la salud de los trabajadores y de los ecosistemas. Empresas donde se introducen cambios en las tecnologías administrativas, delegan a los operarios responsabilidades que los hacen transitar por más de un frente de trabajo, no pudiéndose asociar una patología o síndrome laboral con un oficio único o con un factor de riesgo único.

Trabajadores polivalentes desarrollan a la vez distintas actividades del ciclo de producción, incluidas las relacionadas con el manejo de residuos. Procesos no flexibles, entran cargas contaminantes más o menos constantes, las cantidades de residuos peligrosos dependen de las condiciones de demanda y oferta de los productos en el mercado. De ahí que una valoración cuantitativa de los riesgos, resulte siempre en una aproximación.

Es bien sabido, que en los procesos productivos y particularmente en el manejo de los residuos industriales, aparecen nuevos factores de riesgo asociados al manejo de sustancias cuya composición es desconocida por los trabajadores y cuyos efectos en la pérdida de bienestar y desgaste psicofísico, directo e indirecto, son desconocidos también. En la producción industrial se generan unos subproductos en general considerados inútiles y por consiguiente, catalogados como desechos. Las materias primas 
utilizadas en los procesos productivos, pueden ser peligrosas y estas características pueden ser las mismas de los desechos. Sin embargo, durante el proceso muchas de las características peligrosas, pueden modificarse, atenuándose o potenciándose.

No es fácil emprender la detección de las diferentes sustancias industriales, que resultan como residuos en los diferentes momentos de los procesos; determinar cuáles son los factores de riesgo asociados a tales residuos y emisiones, es en consecuencia igual o más complejo. Algunos de los riesgos que puedan traer los residuos industriales o de cualquier otra procedencia, están asociados a las características fisicoquímicas, biológicas y tóxicas, que dependen de la composición de los mismos, independientemente de su estado físico:

(i) Patógenos, cuando por sus características y composición pueden ser reservorio o vectores de patógeno (biotecnologías, industrias de alimentos).

(ii) Tóxicos, dependiendo de la concentración, tiempo de exposición y características metabólicas de los expuestos.

(iii) Combustibles e inflamables, que arden al oxidarse o con presencia de una fuente cualquiera de ignición.

(iv) Explosivos, que generan golpes de presión por su descomposición espontánea.

(v) Radioactivos, que emiten radiaciones nucleares.

(vi) Volatilizables, las que por su presión de vapor a temperatura ambiente cambian a fase gaseosa.

Al respecto, entidades especializadas en higiene industrial han elaborado listas de sustancias peligrosas, resultantes de diferentes procesos productivos. Estas sustancias no solamente producen efectos por su toxicidad la cual depende de las características fisicoquímicas de las sustancias, del tiempo de exposición, de la dosis, de la concentración, de las vías de ingreso al organismo, del metabolismo de las personas expuestas, del género de las condiciones locativas y de las condiciones atmosféricas, etc., sino también de otros residuos que pueden ser de naturaleza patógena, provocar procesos biológicos degenerativos o condiciones adversas que induzcan conductas neuróticas o psicóticas, o cualquier tipo de patologías físico-mentales.
Para cambiar el tipo de desechos indeseables por alguno deseado, se requiere hacer modificaciones al proceso. Estas se hacen o se evitan bajo consideraciones económicas inmediatistas. Desde una perspectiva de la economía ambiental, habría que cargar a las utilidades, aquellas que obtendrían las generaciones futuras y presentes a partir de las innovaciones o cambios tecnológicos que se efectúan. Del criterio de rentabilidad o de ganancia, debe trascenderse para dar cuenta de los costos sociales y ambientales, lo que seguramente permitirá enfocar la aplicación de tecnologías limpias, bien sea mediante manejos especializados de los residuos, cambios en la organización del trabajo o transformaciones físicoquímicas, siendo necesario asegurar unos criterios de producción justa y ética.

\section{Contaminación industrial}

La transformación de materia que se produce en la industria nunca es total, generándose residuos en forma de energía o de materiales, los cuales si no son recuperados y reutilizados, se convierten en contaminantes susceptibles de producir daños sobre la naturaleza, alterando la abundancia y los tipos de especies vivas, perturbando los sistemas físicos y biológicos y modificando los niveles de radiación y de reparto de energía.

Lo nocivo de la contaminación sobre los ecosistemas y sobre la vida que en ellos se desarrolla, depende entre otros parámetros, de la facilidad de dispersión de los contaminantes, de los desplazamientos a distancias más o menos considerables que, debido a la gran complejidad biogeoquímica de la biosfera, pueden alterar ecosistemas lejanos. Lo nocivo también depende de la posibilidad de transformación de los contaminantes en otras sustancias más peligrosas o dañinas y de la acción conjunta y simultáneamente de varios contaminantes y determinados factores ambientales y sus posibles efectos aditivos, acumulativos o sinérgicos.

Con frecuencia el método más económico para eliminar los desperdicios industriales líquidos, consiste en descargarlos al sistema municipal de alcantarillado. Se debe determinar si hay competencia por el uso de los servicios públicos de alcantarillado. En 
la mayoría de los casos las plantas de tratamiento en los alcantarillados, dependen de procesos biológicos complejos, que pueden verse alterados por muchos desperdicios industriales. En muchos casos, no hay claridad sobre en quién reposa la responsabilidad de los cursos de agua y quién cuida que se evite su contaminación. Hay algunas normas que establecen los límites de aceptación de los desperdicios que hayan de ser descargados al alcantarillado, pero suelen ser desacatadas.

En el caso de los complejos industriales, las alcantarillas han de estar protegidas contra acciones corrosivas y cargas pesadas de desperdicios altamente alcalinos o ácidos, eliminando así el peligro de que el proceso de tratamiento biológico sea perturbado. Los antecedentes de la explosión de alcantarillas en México, como el insuceso en Cali, que condujo a la intoxicación de pobladores de inmediaciones de la zona industrial, por efecto de gases clorados provenientes de las alcantarillas, son ejemplos claros del inadecuado manejo de los residuos. Los desperdicios inflamables y tóxicos, no pueden ser arrojados indiscriminadamente con los demás desperdicios y se debe prohibir el vertimiento o descarga a estos conductos, de tóxicos volátiles, así como de desperdicios calientes de sustancias ácidas o alcalinas que pueden hacerse más corrosivos.

De los anteriores planteamientos, se deduce que es inminente apoyar a las PYMES en el manejo adecuado de los residuos, porque seguramente estas se preocupan mas por los mecanismos de producción y muchas veces por desconocimiento, no toman las precauciones debidas, ocasionando alteraciones que representan daños incalculables a las personas y al medio ambiente.

\section{Conclusiones}

\section{Hacia una intervención sistémica}

Se ha podido observar que el manejo de la problemática ambiental entendida como un sistema complejo exige la profundización en el conocimiento del componente natural desde diferentes aspectos: su funcionamiento, sus desequilibrios, las causas internas y externas de los conflictos, la proyección a futuro de los mismos y para entenderlos se deben enfocar con la visión de los aspectos del contexto social, económico y cultural, que permitan el entendimiento de las dinámicas integradas que lo modulan. Se puede concluir, que para dimensionar la interacción de todos estos componentes, se requiere que el análisis de los mismos se de, desde las diferentes especialidades, las cuales integradas serán capaces de responder de manera precisa y adecuada a las exigencias.

Para responder a las anteriores debilidades, se debe partir de acciones científicas direccionadas por la investigación, la ética y la estética y la interdisciplinariedad que de ninguna manera actuarán de manera excluyente, sino que al contrario se presentan como condiciones complementarias que pueden actuar de manera interdependiente. De esta forma, se consigue que se aporten elementos fundamentales, para el análisis de la problemática ambiental porque se enriquece la argumentación desde la visión profunda y especialista de cada disciplina que confluyen para nutrir explicaciones en lo particular, pero que a la vez abren posibilidades para la comprensión global. Esta ampliación e integración de saberes solo se logra mediante la combinación interdisciplinaria, que permite un diálogo permanente de saberes.

En este contexto, la comprensión de un problema ambiental requiere de la participación e integración de diferentes áreas del conocimiento, disciplinas, conceptualizaciones y metodologías. Éste, "el medio ambiente" se concibe no solo desde el resultado de la dinámica del sistema natural, es decir, de orden físico, químico, biológico, sino de esencia social, de orden tecnológico, económico, cultural y político. Es decir que, no es posible reducir el término ambiental, a la conservación de la naturaleza, a la problemática de la contaminación por basuras o a la deforestación. En consecuencia, en la presente propuesta se aúnan esfuerzos y se integran conocimientos, desde disciplinas diferentes, tales como la sociología, la gestión ambiental y la economía.

\section{Referencias}

1. Campuzano S, Camacho J. Medio Ambiente- Salud: un modelo de aplicación. Imprenta Nacional. Bogotá UCMC. 2009

2. Organización de Naciones Unidas. ONU 2002

3. Daly H. Economía. Ecología y Ética. Fondo de Cultura Económica. 1989.

4. Política Nacional de Educación Ambiental. SINA. Ministerio del Medio Ambiente. Ministerio de Educación Nacional 2002 
5. Torres Carral, Guillermo. El pago de servicios ambientales y las comunidades indígenas. Ra Ximhai, 2006( 2): 187-207

6. Kollinger, A. Globalization and national incentives for protecting environmental goods. Max Plank Institute for Research on collective goods. Bonn. 2004: 70-75.

7. Stavins, R. Introduction to the political economy of environmental regulation .Chapter 1. Edwuard Elgar Publishing. Inc. John F. Kennedy School of Government. Harvard University. 2004:87 -92.

8. Jiménez, Luis. Desarrollo Sostenible y Economía Ecológica. Integración medio ambiente-desarrollo y economía-ecología. Editorial Síntesis. Madrid. Cap. 1 1997:

9. Guimarães, Roberto: La Ética de la sustentabilidad y la formulación de Políticas de desarrollo. En Ecología Política, Naturaleza, Sociedad y Utopía. Compilador Alimonda Héctor.2003

10. Daly H. Criterios operativos para el desarrollo sostenible.

11. http://www.eumed.net/cursecon/textos/Daly-criterios.htm

12. Carrizosa, J. Construcción de la Teoría de la Sostenibilidad. En Revista Transición, Convivencia y sostenibilidad, No.5. SantaFé de Bogotá. 1998 p 28

13. Costanza Daly, H. y Bartholomew J: Goals, Agenda, and Policy Recommendations for Ecological Economics. En: Ecological Economics. The
Science and Management of Sustainability. Ed: Costanza, R. Impreso por Universidad de Columbia. Nueva York. 1 - 20 p.1991.

14. Costanza, R., y Gottlieb, S. : Modeling Ecological and Economic Systems with STELLA: Part II. Ecological Modelling, 1998(112):81 - 84 .

15. Costanza, R. y Voinovich, A. : Modeling Ecological and Economic Systems with STELLA: Part III. Ecological Modeling, 2001 143:1-7.

16. Tchobanoglous, George. Et al:: Gestión Integral de Residuos Sólidos. Mc Graw-Hill. 1996(1).

17. Martínez A, Jusmet J. Economía ecológica y Política ambiental. Programa de las Naciones Unidas para el Medio Ambiente. Fondo de Cultura Económica. México. 1998

18. Castiblanco Carmenza.: Notas Valoración Económica de Bienes y Servicios Ambientales. Universidad Nacional. IDEA. 2006.

19. Bejarano A. Desarrollo Sostenible: Un enfoque económico con una extensión al sector agropecuario. ICA. Ministerio de Agricultura y Desarrollo Rural. Colombia.1998

20. Ángel M. Desarrollo sustentable o cambio cultural. En: la gallina de los huevos de oro. Debate sobre el concepto de desarrollo sostenible. Bogotá: CEREC-ECOFONDO 1998.

21. Ángel M. La tierra herida. Las transformaciones tecnológicas del ecosistema. Cuadernos Ambientales N 2. Bogotá. Universidad Nacional. 1994.
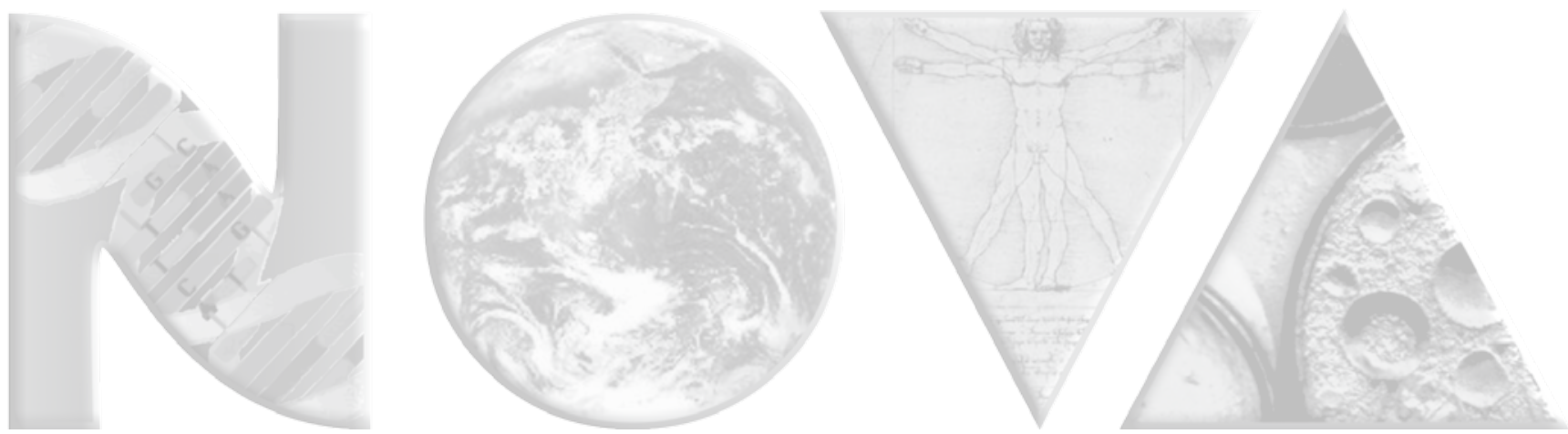